\title{
Del Discurso a la Performance: La Producción de Significaciones de Nacionalidad en el "Jazz Argentino"
}

\section{Berenice Corti}

\author{
Universidad de Buenos Aires \\ Instituto de Investigación en Etnomusicología de Buenos Aires \\ berenice.corti@gmail.com
}

\section{Resumen}

A partir de trabajos de investigación realizados en torno al jazz argentino, nos enfocamos aquí en los sentidos de nacionalidad construidos en los discursos de y sobre esta música, proponiendo además un enfoque para aquellos producidos en el marco de la performance como espacio de creación de significaciones sociales. Contrastamos esos sentidos con los discursos hegemónicos sobre músicas nacionales en el país, y analizamos de qué forma unos y otros entran en tensión en el marco de la producción de significaciones en y sobre la música. La propuesta incluye también una breve revisión crítica de las discusiones teóricas sobre construcción de sentidos en identidad y nacionalidad, colocándose en la necesidad de ubicar los estudios discursivos también el marco del complejo musical sonido/performance.

Palabras clave: jazz argentino, nacionalidad, sentidos discursivos y performáticos

\begin{abstract}
Within the framework of Argentine jazz studies we focus here on senses of nationalism built in to speeches of and about this music, proposing also a focus about those produced in the context of performance as a productive space of social meanings. At first, we contrast these meanings with hegemonic discourses of nationality in Argentine music, and analyze how both senses present tensions related to the signification processes within and about music. The article also includes a brief critical review of the theoretical discussions on meaning construction around identity and nationality, understanding the need to place the discourse studies as a part of the musical complex sound/performance.
\end{abstract}

Keywords: Argentine jazz, nationality, discursive and performance meanings.

"Recuérdese entonces que todos los discursos son 'localizados', y que el corazón tiene sus propias razones".

Stuart Hall (1996)

En el marco de una investigación sobre jazz argentino, enfocada en sus prácticas de significación relativas a fenómenos de identidad -o más bien, las que suelen referirse genéricamente como tales-, surgió como necesidad metodológica la revisión de diversos aportes teóricos que han contribuido a la discusión reciente de estas temáticas. 
A efectos del presente artículo nos detendremos en unas pocas referencias a algunos procesos específicos de producción de este tipo de sentidos en el jazz argentino, para utilizarlos como llave de acceso a los problemas teóricos que se plantean en el abordaje de la música popular como discurso -en su sentido más amplio del término-, y puntualmente en la producción de significaciones de nacionalidad. Optamos por mencionar entonces sólo ciertos aspectos documentales de la investigación (ver nota 1) que pueden sernos útiles para abrir preguntas de tipo conceptual, pero que entendemos requieren aún un mayor debate. Queremos dejar sentado también que lo que sigue no constituye una propuesta ya acabada sino una aproximación a un trabajo aún en proceso.

\section{Un jazz ¿argentino?}

A fines del año 2001, en coincidencia con la feroz y última crisis socioeconómica que estalló institucionalmente en el país, comenzaron a circular con una mayor asiduidad en las páginas de los medios gráficos de comunicación las referencias a un "jazz argentino". Algunas notas periodísticas mencionaron -por citar algunos ejemplos-, la vitalidad del "jazz nacional" en épocas de crisis (Pradines, 2001), el hecho de que "es tan difícil vivir en Argentina como tocar jazz" (Hojman, 2001), o que la crisis propició una "mirada hacia adentro" y el surgimiento de un "movimiento con identidad propia que genera, por ende, mayor identificación” (García, 2003).

Esta categoría de "jazz argentino" fue utilizada por propios y extraños para la denominación de una cierta nueva música ${ }^{2}$, cuya cristalización de manera no precisa en una suerte de estilo estaría dada por una identidad construida a partir de la incorporación de elementos musicales locales en la práctica del jazz vernáculo. Para algunos se trató del surgimiento de un nuevo jazz argentino, o directamente de un jazz argentino; para otros, de músicos argentinos de jazz que pudieran ser reconocibles cuantitativa y cualitativamente. ${ }^{34}$

Si bien ya en 1967 un disco del pianista Baby López Fürst llevó, precisamente, el título de Jazz Argentino (Melopea, 2005), la novedad del cambio de siglo radicó en que un "relevo generacional" - en palabras de Sergio Pujol (2004, p. 256) - irrumpió con características propias en la escena local ya desde los fines de los años noventa. A diferencia de sus antecesores, sus exponentes no estaban formados -0 al menos no principalmente- en algún ocasional Conservatorio académico, la escucha de discos y las prácticas de la jam session ${ }^{5}$-es decir, tocando-, sino también a través de una educación musical sistematizada y específica de nivel terciario, nacional y extranjera. ${ }^{6}$ La nueva generación optó por un mayor énfasis en la composición propia construyendo una diferencia con respecto a los músicos de mayor edad $^{7}$ a través de la jerarquización cualitativa de la obra de autoría por encima de la interpretación de repertorio standard ${ }^{\beta}$, o de la inclusión de manera literal de elementos musicales entendidos genéricamente como extrajazzísticos - operación referida como característica del llamado jazz fusión de los años setenta y ochenta - (Corti, 2007, pp. 71-74; 2011, p. 15).

Este proceso de constitución de un jazz argentino no estuvo exento de debates hacia el interior del "campo artístico", en el sentido amplio que Pierre Bourdieu (1988) le da al término y que incluye, además de los artistas, a otros partícipes como críticos, periodistas y productores culturales. Por ejemplo, en declaraciones obtenidas de algunos de estos actores en el marco de una mesa redonda en el II Festival Buenos Aires Jazz y otras músicas (2003) se desprende una suerte de imposibilidad argentina del jazz, en razón de que la única identidad posible estaría dada por la individualidad artística personal, lo que fue destacado por los críticos y periodistas Diego Fisherman, Jorge Freytag o el también guitarrista Guillermo Bazzolla. También porque no podría tener rasgos nacionales un género musical que habría alcanzado tal nivel de internacionalidad, lo que estaría hablando de un supuesto carácter universal del 
género (Corti, 2007, pp. 15-16.) Otros músicos, en cambio, sí se refieren a un jazz argentino, por ejemplo, entendido como un movimiento basado en los artistas que lo componen -como propuso el saxofonista Rodrigo Domínguez- "y que no tiene que ver con los elementos musicales que se utilizan", sino, con una "manera común de sentir determinadas cosas, como el ritmo" (Corti, 2007, pp. 16-17). Por su parte, otros integrantes del campo cultural señalaron la novedad de las estrategias discursivas de la generación más joven de músicos o la consolidación de los cimientos de un nuevo circuito artístico (Pujol, 2005; Fondebrider 2005, apud Corti, 2007, p. 17).

Esta pequeña muestra de significaciones que enlazan prácticas musicales y discursos identitarios describe la forma en que se producen disputas por sentidos nacionalizados de la identidad en los discursos nativos sobre la música, en el sentido en que los estudios antropológicos definen a los discursos producidos por los actores, en este caso, del campo artístico. Constituye una primera capa de análisis para diferenciar, por decirlo de algún modo, lo que se dice de la música de lo que dice la música, como uno de los juegos específicos de discurso que tienen la capacidad de articular el espacio simbólico de la música y la identidad.

Si pensamos en algunas de sus características más relevantes, podemos decir que además de mostrarnos a la identidad como social y procesualmente construida, estos discursos nativos sobre la música entienden (y refieren) la cultura y la música a partir de un centro territorial. Esto conlleva, según José Jorge de Carvalho y Rita Segato (1994), un enmascaramiento de los procesos de creación y recepción de las músicas por medio de la concepción -o construcción- de la música como receptora de atributos de nacionalidad. Se trata de un tipo de significación que puede ser encontrado en todo tipo de discursos nativos incluyendo los científicos y/o críticos de los analistas", y que, según estos autores, es creado a partir de un "hábito de pensamiento" que produce identificaciones y que operan a su vez sobre las identidades sociales, mediante procesos de territorialización, estereotipación y fetichización (Carvalho y Segato, 1994, p.3).

Podemos conectar esta propuesta con la precisión que Stuart Hall (2003) realiza del concepto -entrecomillado- de "identidad cultural", al que pone en cuestión a la vez que lo enuncia: esta sería una "expresión" no problematizada de la autoridad y autenticidad, producto de la utilización de una definición unicista, estable y continua de la identidad. Siguiendo a Hall, para quien las llamadas identidades culturales son "puntos de identificación inestables hechos en el interior de los discursos de la cultura y la historia. No es una esencia, es un posicionamiento" (Hall, 1996, p. 70), retomemos la problemática de la disputa por los sentidos discursivos: en tanto la cuestión del poder es clave en la organización de prácticas y discursos, las identificaciones culturales implican un posicionamiento estratégico en relación a ese poder. También, la representación sería clave en la construcción de identidades, por cuanto para Hall ésta se realiza dentro y no fuera de ella (Hall, 2003, p. 18), es decir, en la producción de discursos. Al respecto incluiremos algunas consideraciones más adelante.

Carvalho y Segato describen a los discursos nativos como metafóricos, fundados en procesos de estereotipación de las identidades sociales sobre la base de los emblemas musicales, o racionalizadores, que construyen a la música como un fetiche para llenar la "necesidad de fijación de identidades de los grupos sociales emergentes" (Carvalho y Segato, 1994, p. 10).

De esta forma, los ejemplos citados en la primera parte de este artículo pueden ser incluidos en la categoría de discursos nativos de segundo grado de tipo racionalizadores, porque se distinguen por su capacidad para la construcción de fetiches musicales que a su vez satisfacen la necesidad de fijación de las identidades sociales. Esa idea de fetiche puede relacionarse también con el totemismo contemporáneo que propone Michel Maffesoli (apud Carvalho y Segato, 1994, p. 10), o, podríamos agregar, a los "productos de la mente humana", imaginarios y 
fantasmáticos, que parecen dotados de vida propia y enmascaran las condiciones sociales de existencia según Marx (1964, pp. 36-47). Pensamos aquí en ideas como arte puro, música universal, espíritu creador libre ${ }^{10}$, y, por qué no, música nacional.

La fijación del fetiche también puede verse como una necesidad de "afirmación indirecta de la inadecuación o el carácter inconcluso de lo que es", en palabras de Zygmunt Bauman (2003, pp. 41-42), por lo que el fetiche puede ser leído tanto como una estrategia posicional o como un efecto mismo de la reproducción cultural.

En cuanto a los discursos metafóricos -como estereotipación de identidades sociales basados en emblemas musicales- veamos un ejemplo volviendo a nuestro campo de estudio. Una mirada más o menos rápida sobre las formas de denominar estilos y géneros musicales en programaciones de conciertos de jazz de Buenos Aires, brindadas por los músicos para describir el tipo de música que interpretaban en sus conciertos $^{11}$, nos proporciona el siguiente listado de géneros asociados a diferentes emblemas musicales: tango; tango contemporáneo (por tango no tradicional); folklore (por lo que se conoce como folklore argentino, música popular asociada al ámbito rural); folklore contemporáneo (por folklore argentino no tradicional); latin (por estilo latin jazz); rock; música afrorrioplatense (por candombe estilo uruguayo); candombe (por candombe estilo uruguayo); música latinoamericana (por música popular latinoamericana); y música contemporánea (por música erudita contemporánea), entre las más relevantes.

Estas categorías han sido y son organizadas socialmente de manera estereotípica en relación al par nacional/no nacional, por lo que las músicas locales se revelan sólo en el tango, el folklore -cuando no lleva la adjetivación de latinoamericano- y el rock, en este último caso cuando es citado algún artista especialmente valorado, como puede ser el caso de Luis Alberto Spinetta ${ }^{12}$. Todas estas músicas son citadas como plausibles de dialogar con el jazz. ${ }^{13}$

Lo no nacional aparece en todas las otras denominaciones genéricas: en primer lugar en el mismo jazz, en razón de que cuando son citados nombres de compositores no se reconocen referentes argentinos -aunque el jazz lleve ya casi un siglo de existencia en Argentina-. El jazz latino es preponderantemente denominado con su voz en lengua inglesa latin, es decir, como tipo de música en tanto género específico producido por latinos en los Estados Unidos, pero también como construcción allí realizada sobre qué es lo latino en el jazz. ${ }^{14}$ El candombe sólo puede ser uruguayo ${ }^{15}$, y las músicas que utilizan tambores refieren a lo popular regional no local, o africano -esto último en términos amplísimos-. De esta forma, podríamos decir que el jazz y otras músicas afroamericanas aparecen -a priori- ocupando el lugar de lo no nacional, por lo que la interpretación de este abanico musical de matriz africana puede hacerse sólo desde una conciencia de su ajenidad. Esto tiene que ver con que la racialización del jazz en la Argentina como música "negra" no es simplemente -0 solamente- producto de una lectura esencialista y biologizante de su supuesta identidad como género musical, sino el resultado de un trabajo -"work,en el sentido de trabajo de construcción social de la realidad" (Frigerio, 2006, p. 81)-, que operó y opera en niveles micro y macro sociales para ubicar lo negro, lo afro, lo africano, por fuera de un imaginario nacional, tanto a través de la invisibilización de la presencia de afrodescendientes en la historia argentina como de sus rasgos fenotípicos en la población del país. Consecuentemente, si en el proyecto de Nación Argentina no hay lugar para negros argentinos, no es posible pensar lo negro como argentino, produciéndose una imposibilidad ya no sólo para la existencia de una cultura negra y argentina en el país, sino también de una mera condición mestiza. 


\section{Músicas nacionales y músicas nacionalizadas}

Entre las condiciones de producción de los discursos de nacionalidad sobre la música, tanto en el caso de Argentina como en el resto de Latinoamérica, se encuentran los procesos de constitución de los Estados Nación y sus discursos nativistas que buscaron sentar las bases para la construcción de las identidades locales (Madrid, 2010a, p. 227). Éstos apelaron en su mayoría a una idea homogeneizadora de conformación de las culturas nacionales, como pueden ser, entre otras, las llamadas doctrinas del mestizaje o de la blanquedad (Corti, 2010), y que logran encubrir los procesos de estratificación social y cultural en sus respectivas sociedades.

Citemos como ejemplo este párrafo del folclorista y padre fundador de la musicología argentina Carlos Vega, que intersecta muchas de estas cuestiones:

Indígenas, conquistadores y negros africanos han recibido, pues, su parte en la distribución [de la paternidad del cancionero popular en América]. Las vidalas y vidalitas fueron atribuidas a los incas, o a los diaguitas y calchaquíes; los españoles merecieron gatos y chacareras y, por fin, los abnegados y fieles negros fueron recompensados con el reconocimiento de su aporte de zambas, milongas y tangos. La donación de un puñado de melodías a un pueblo, por compensación de servicios, denota exquisito gusto y hasta elegancia sentimental y bien merece el gesto cierto desdén por la verdad histórica. El caso es que por obra de la distribución proporcional se afirma que tenemos música africana en el cancionero argentino. Los músicos que se han ocupado de estas cuestiones lo han entendido así. (...) Los escritores, por su parte aceptaron la opinión de los músicos e hicieron bien. Por nuestra parte rechazamos en absoluto la influencia africana en la música popular argentina. (Vega, apud Domínguez, 2008, p. 3)

De aquí se desprenden esas disputas de sentido sobre nacionalidad y racialidad a los que referíamos anteriormente, como el ya muy transitado debate sobre los llamados orígenes africanos del tango. No hace falta abundar aquí en el carácter esencialista y estereotípico de una idea de identidad conceptualizada a partir de un supuesto germen originario. Pero sí queremos señalar que la resistencia de los discursos culturales hegemónicos de nacionalidad a apenas aceptar la posibilidad de una relación del tango con las culturas africanas -aún cuando el vocablo tango así se presente casi inequívocamente, en una conexión que todavía debe esclarecerse aunque más no sea por su operación de borrado- revela una muestra más de la capilaridad de la doctrina de la blanquedad en los discursos sobre la argentinidad. La paleta de alternativas a la posibilidad africana del tango es amplia: uno, la negación total como en Carlos Vega; dos, la explicación de un origen español de la habanera con una consecuente conexión europea del tango, operación de perífrasis que señala y documenta Gustavo Goldman (2008) ${ }^{16}$; tres, la dilución de la estirpe africana en la música a partir de la desaparición de los afrodescendientes (Ortiz Oderigo, 2009) ${ }^{17}$; o cuatro, el énfasis de algunos letristas de tango en ubicar a los afrodescendientes en el pasado (Cirio, 2006).

Algunas de estas estrategias fueron utilizadas también para identificar al complejo sonoro performático carnavalesco murga sólo con géneros europeos de función similar, lo que es puesto en cuestión por el trabajo etnográfico de Alicia Martín (2006) realizado con la población afroargentina cultora de la murga por varias generaciones. Por su parte Pablo Cirio (2010) también documenta la "historia negra" del tango a través del relevamiento de la activa participación de músicos afrodescendientes en las agrupaciones musicales del género, desde los tiempos de la denominada Guardia Vieja hasta la actualidad ${ }^{18}$. Pero esto, por supuesto, no garantiza ni la africanidad.ni la afroargentinidad del tango, así como la supuesta desaparición de afrodescendientes tampoco garantizaría su desafricanización. De todas formas, ha sido denominador común de los discursos nativistas sobre la música nacional en 
Argentina la construcción del tango como música blanca, convirtiéndose ésta en una de sus características más salientes.

Otro aspecto relevante está relacionado con lo anterior y tiene que ver con la identidad pensada como homogeneidad, operación que puede ser encontrada también en los discursos sobre la música popular conocida como folklore. Al respecto, Claudio Díaz (2009) describe cómo se constituyó este campo artístico y cultural en torno a tres momentos clave: la creación de una ciencia del folklore a fines del siglo XIX relacionada con la constitución de la nueva sociedad moderna; su esbozo como "arte nacional" propiciado por las corrientes nativistas y tradicionalistas hasta bien entrada la década de los cuarenta; y su consolidación como música popular por sobre la plataforma de la industria cultural, esto último en el marco del proyecto político del primer peronismo que abogaba por una cultura de unidad nacional. ${ }^{19}$ Estos procesos fueron acompañadas a su vez por el desarrollo de "proyectos esencialistas de investigación musicológica que validaron esas músicas como emblemas de la nación", como dice Alejandro Madrid (2010b), y que "se dieron la mano con la construcción de los mismos Estados nacionales y con los discursos nacionalistas que pretendían naturalizarlos". La marca de nacionalidad en los discursos nativistas argentinos estuvo puesta en figuras como la del gaucho, que cumplió el rol de catalizador simbólico para la adecuación de las categorías raciales al proyecto de modernidad argentina blancaeuropea (Corti, 2011). ${ }^{20}$

\section{Naciones discursivas y naciones performadas}

El otro espacio de producción de significaciones en donde también pueden analizarse los sentidos de nacionalidad es el que incluye tanto al discurso propiamente musical en el acto de hacer música, como a la participación en la semiosis musical por medio de la performance creativa y la recepción activa, es decir, el marco de la Músicopoiesis (Carvalho y Segato, 1994, p. 5).

Ésta puede constituirse como mirada posible en tanto nos ocupemos de la producción de significaciones como manifestación de fenómenos sociales, en una adaptación al campo artístico de la perspectiva de la sociosemiótica de Eliseo Verón (1987). Pero para ello debemos establecer, en primer lugar, una distancia crítica con respecto a la semiótica musical de Jean Jacques Nattiez y Jean Molino: aunque ambas visiones del análisis discursivo están basadas en la semiosis ilimitada y en la tripartición del signo peirciana -y por consiguiente en la música como formación simbólica-, la estrategia formalista de Nattiez y Molino fija al discurso en su manifestación visual, su código, su representación escritural, jerarquizando la elaboración racional de la música por sobre su materialidad sensible. Como dice Phillip Tagg (2000 [1982], p. 4) esta vertiente de la semiótica musical puede equipararse a una semiótica de la art music occidental, por lo que tampoco nos resulta útil para el análisis de músicas populares principal o totalmente no eurocentradas.

En contraste, el sentido -además de estar construido socialmente y restringido por condiciones determinadas en las tres instancias que conforman un sistema productivo: producción, circulación y reconocimiento-, presenta una manifestación material o "paquetes" de materias sensibles investidas de sentido que son los productos -en este caso, musicales-, a partir de los cuales se accede mediante su análisis a los procesos que los hacen posible (Verón, 1987). En la misma línea, Philip Tagg (2000 [1982]) ha propuesto la consideración del significado y el sentido en la música, en el canal sonoro, como modo de acceder a la comprensión de la música inserta en su contexto ${ }^{21}$ global. De todas formas preferimos aquí la utilización del concepto de condiciones de producción, más concretas e explícitamente ideológicas que la mera descripción de un contexto o marco, lo que suele encubrir los procesos productivos que intervienen en esas significaciones. 
Este énfasis en lo sonoro y en su producción como práctica social de significación pretende avanzar por sobre las concepciones del sonido como reflejo social o como mero envoltorio de un significado cerrado y unívoco. Al respecto, varios autores ya han revisado críticamente las variadas perspectivas que se han ocupado de la significación musical en materia de identidad, por lo que no repetiremos esa revisión completa aquí. Aún así a manera de ejemplo podemos mencionar a Pablo Alabarces (2005) quien ha criticado aquellas de corte sociológico que opacan las consideraciones estéticas, el cuerpo y las cuestiones sobre poder simbólico, caracterizándolas como incompletas. O a Luis Ferreira (2008b, p. 34), quien señaló que han fracasado las tentativas de explicar la estructura musical por la estructura social -y a la inversa-, lo que indica que el sonido musical "no es denotativo sino un significante arbitrario". Esta propuesta se encuentra a su vez en sintonía con el señalamiento de Carvalho y Segato acerca de que en la base misma de la Etnomusicología como ciencia se encuentra el modelo analítico aproximado a la homología bourdieana que se establece "entre clivajes sociales y sus correspondientes categorías simbólicas musicales" (1994, p. 9). En este mismo sentido Pablo Vila $(1996,2000)$ se refirió a lo que denomina "la visión homológica" que entiende a la música como un reflejo de la estructura social.

Realicemos un anclaje de estas cuestiones en el marco de ejemplos específicos. En la primera etapa de nuestra investigación trabajamos en el abordaje de la música como discurso, es decir, el análisis de la materia significante o de su manifestación material para dar cuenta de los procesos que la hace posible: entre éstos, las prácticas de composición escrita y su representación en la partitura como condiciones de producción del complejo sonoro/performático. Nos ocupamos de tres obras compuestas por músicos argentinos de jazz: "El Compadre" (Acqua Records 2001) del Quinteto Urbano, "Chacarerosa" (MDR Records 2006) del grupo Escalandrum y "La Academia" (S'Jazz 2005) del grupo del baterista Pepi Taveira. Estas obras incluyen esos elementos que algunos discursos nativos -como veíamos más arriba- caracterizan como determinantes para constituir a esta música como "jazz argentino"; dicho de otro modo, aquellos emblemas musicales sobre los que se construyen los estereotipos de la música nacional argentina. $O$, en términos de Acacio Piedade, los tópicos musicales -como noción para una teoría de la expresividad y del sentido musical que permite identificar unidades de sentido en motivos o frases melódicas y/o rítmicas o secuencias armónicas- que al margen de sus características intrínsecas otorgan significación en el discurso en virtud de la posición que en él ocupan, capacidad que puede ser experimentada tanto por los performers como por la audiencia (Piedade 2005, pp. 3-4). Por ejemplo, la clave rítmica 3-3-2 característica de la milonga y resignificada por Astor Piazzolla ${ }^{22}$, la utilización de compases de 6/8 y $12 / 8$ como modo de referir al género folklórico de la chacarera ${ }^{23}$, o texturas que remiten a la sonoridad de la murga (Corti, 2007).

Aunque se trata éste de sólo uno de los aspectos de la Músicopoiesis, el discursivo sonoro, el análisis nos permitió sintética y provisoriamente arribar $\mathrm{a}^{24}$ :

1) Es en una fase primaria de composición de autor donde se incorporan elementos/emblema tomados de la música popular argentina mediante la forma de tópicos -ajenos a la conocida como de tradición musical jazzística- pero con una intención de relectura y reinterpretación. Se trataría de una revalorización del rol del compositor -individual o grupal- en un género musical cuyas prácticas a nivel local se basaban en gran medida en la reproducción y/o reinterpretación de repertorios ajenos. De esta forma, el sujeto discursivo irrumpe haciendo explícitas sus condiciones de producción, las que son referidas como influencias de formación, gusto, entorno social y cultural. También es posible distinguir un grado de utilización de los elementos locales mediante una operatoria diferente a la del jazz referido como de fusión, en donde las unidades de sentido discretas de los emblemas musicales tienen un 
funcionamiento discursivo más estable y una referencialidad explícita, incluso en una cuasi literalidad.

2) La performance es el espacio de fase secundaria de la composición, ahora grupal, que se construye en la interacción entre músicos fundamentalmente a través de la práctica improvisatoria. Funciona, por un lado, como lugar de búsqueda estética para la confluencia colectiva del sonido e ideas musicales, y, por el otro, como vía para una exploración imaginaria de identidades que aborda precisamente el conflicto aparente de las diferencias, tensión devenida de la utilización de elementos socialmente reconocidos como provenientes de diferentes tradiciones musicales. La improvisación emerge entonces como gramática de producción del discurso ${ }^{25}$ operando en dos niveles: uno, como herramienta interpretativa/compositiva en su sentido estricto cuya definición clásica refiere al "modo de ejecutar en forma espontánea, sin música escrita” (Schuller, 1973, p. 396), es decir, como el Otro de la composición eurooccidental en términos de Nicholas Cook (2007, p. 15). Y dos, también como "contexto [...] marcado por el mensaje: 'éste es el juego"" (Nachmanovitch, 1991, p. 59), que implica un nosotros intersubjetivo que comparte no sólo un durée interior, sino un presente simultáneo y vívido de la corriente de conciencia del otro en su inmediatez, como diría Alfred Schutz (1977, p. 210). La composición grupal en tiempo real, esa improvisación que resulta una doble performativización del topos y del cronos, es como tal capaz de producir sentidos que pueden no coincidir con los de la fase primaria de composición de escritura.

3) El dispositivo discursivo de la llamada y respuesta -que se desarrolla en y con la estructura musical formal de la antífona- también surge como gramática discursiva y nos permite pensar los diálogos rítmicos como una puesta en discusión de las diferencias musicales, culturales, sociales y estéticas, como estrategia de apertura y de experiencia de una identidad que puede ser elegida 0 no, imaginada $y / 0$ practicada. Podemos acceder así a la identidad no como un lugar de sentido, de significación determinada y determinante de una esencialidad, sino más bien como un proceso de construcción simbólica inscripta en una cadena de semiosis ilimitada, que enlaza tanto representaciones como prácticas.

\section{Del discurso a la performance}

El concepto mismo de Músicopoiesis propuesto por Carvalho y Segato supone una producción de sentido discursiva y performática, es decir, la posibilidad de la música para la producción de una capacidad doble de significación. Esta perspectiva también es sostenida por Luis Ferreira quien menciona la existencia de una codificación embutida dentro de un código preferencial en la práctica musical, lo que posibilita la construcción de al menos dos sentidos o "doble voz" (Ferreira, 2007, p. 14; 2008a, p. 227).

Pablo Vila trabaja también la relación en la música entre dos núcleos de sentido, enfocándose en el proceso dialéctico que habilitaría "a los actores sociales [a] ajustar las historias que cuentan para que las mismas 'encajen' en las identidades que creen poseer", por un lado, y que al mismo tiempo "permite que dichos actores 'manipulen' la realidad para que la misma se ajuste a las historias que cuentan acerca de su identidad (Vila, 1996). Pero el énfasis está puesto aquí en el concepto de música como artefacto que "provee a la gente de diferentes elementos que ellos utilizarían, al interior de tramas argumentales, en la construcción de sus identidades sociales", es decir, en los núcleos narrativos que poseen el poder organizador en la producción de identidad (Vila, 2000, pp. 350-360).

Polemizando con Simon Frith, para Vila no habría otra forma de entender la identidad social "básicamente relacional y procesal [...] que no sea a través de una narrativa" (Vila, 2000, p. 362), a la que le adjudica la función amalgamadora de la relación entre imaginario y cuerpo y una centralidad por sobre lo que Frith denomina 
"las experiencias directas que [la música] ofrece del cuerpo, el tiempo y la sociabilidad [...] que nos permiten ubicarnos en narrativas culturales imaginativas" (Frith, 2003, p. 212).

Entendemos que la falta de énfasis de Frith en la narratividad se debe a la distinción que realiza entre la "política de transfiguración [que] impulsa hacia lo mimético, dramático e interpretativo" característico de las músicas de la diáspora africana -por un lado-, de la política de la realización occidental racional presente en la asimilación "de lo semiótico, verbal y textual", como propone citando a Paul Gilroy (Frith, 2003, p. 199), la cual no sería más que la propiedad dominante de la cultura eurocentrada. Podemos agregar otra característica diferencial relativa a la concepción de la temporalidad en el hecho musical: aquellas que presentan un tipo de organización circular son escasamente asimilables a la linealidad logocentrada de las narrativas y a su tipo argumentativo de conocimiento, como sucede en las prácticas musicales africanas y afroamericanas inscriptas en esta manera particular de concebir el tiempo vital y todo lo que en él se incluye, como la música (Chernoff, 1979; Kwabena Nketia, 1974).

Por nuestra parte, y en un nivel muy sencillo, hemos podido observar que en el discurso musical de músicos argentinos de jazz coexisten de manera paralela ciertos sentidos identitarios producidos en procesos narrativos argumentales -por un lado-, y otros que podrían no coincidir completamente con éstos, disparados en el marco de lo performático. Esta diferencia pudo percibirse según se trate, tal como indicamos más arriba, de la fase de composición de autor o de la fase de composición grupal: el color local con su sentido nacionalizado es explícito en el primer caso, pero no así como "trama argumental" organizadora del segundo, es decir, en la práctica de la improvisación.

Entonces ¿cómo pensar un "argumento" o una "narrativa" en una sesión improvisatoria? ¿No están poniéndose en juego allí otras cuestiones menos nombrables, menos narrables, más afines al orden de las sensibilidades como dice Luis Ferreira (2005) o de las musicalidades, en términos de Acacio Piedade (2003, 2005, 2011)? Algunos de los límites del logos discursivo fueron señalados por los mismos músicos de jazz a lo largo de la investigación etnográfica, tanto como imposibilidad de expresar en palabras la experiencia musical o como la falencia de la educación musical formal en asumir lo que no puede ser transmitido en términos verbales (Corti, 2011). De esta forma se abren al análisis de la música otras vías de acceso más situables en el cuerpo y las emociones, menos dichas en términos de lenguaje pero sí expresadas en discursos no lingüísticos, a través de cuerpos significantes (Rocha Alonso, 2004, p. 7). Después de todo, como dice Herman Parret, el "grano de la voz" de Roland Barthes persiste en la música instrumental como "cuerpo dentro de la voz que canta, dentro de la mano que escribe, dentro de los miembros que ejecutan" (Parret, 1995, pp. 90-91).

Si pensamos este doble proceso de significación en términos de la producción de sentidos de nacionalidad, el concepto de Rita Segato (2007) de formaciones nacionales de alteridad nos resulta especialmente útil:

Con ellas se enfatiza la relevancia de considerar las idiosincrasias nacionales y el resultado del predominio discursivo de una matriz de nación que no es otra cosa que matriz de alteridades, es decir, de formas de generar otredad, concebida por la imaginación de las elites e incorporada como forma de vida a través de narrativas maestras endosadas y propagadas por el Estado, por las artes, y por último, por la cultura de todos los componentes de la nación (Segato, 2007, p. 29).

Las narrativas maestras son las que cumplen el rol de tramas argumentales organizadoras de la producción simbólica de identidad, mediante la invocación de emblemas musicales ajustados a identidades nacionales imaginadas. Esto implica a su vez una participación en las disputas por la legitimidad del hecho musical en el arco 
de las músicas nacionales, en este caso como jazz argentino, y contribuye a constituirlo como nueva forma de arte de la sociedad bonaerense post crisis de comienzos de siglo (Wortman, 2009, 30).

Pero en la subyacencia de esa matriz positiva de nación productora de alteridades, reveladora de un "terror étnico" ciego a la no-blanquedad, se encarna otra expresada como su negatividad (Segato, 2007, p.30). En ella el Otro con "la marca del indio o el africano" como signo inscripto en el cuerpo sólo es pensado como extranjero -como no-nacional y también en su sentido más radical de un Otro como extrañocorporeizado como presencia ausente, según la figura propuesta por Alicia Martín (2006).

De esta forma, así como la hegemonía "no deja de tener sentido y, eventualmente, ser activada con otro signo ideológico por los sectores subalternos" (Segato, 2007, p. 30), pensamos que la normatividad expresada narrativamente en la músicopoiesis puede ser resignificada y/o puesta en cuestión en el espacio de lo performático, en donde el cuerpo constituye el sujeto privilegiado de la "doble voz" en la práctica musical.

\section{En busca del sentido perdido}

Para finalizar nos gustaría introducir algunos apuntes sobre la cuestión de la producción de significaciones en la performance musical.

El énfasis en los aspectos narrativos de lo discursivo ha constituido uno de los nudos de cuestionamiento al llamado "giro lingüístico" también relativo a temas de identidad (Cerulo, 1997; Howard 2000). Stuart Hall, por ejemplo, para quien la representación es el espacio dentro del cual se construyen las identidades, sostiene la necesidad de pensar la distintividad -más que la identidad- en relación a las lógicas "dentro de la cual el cuerpo racializado y etnitizado se constituye de manera discursiva" (2003, p. 36). Es decir, no hay discurso sin cuerpo, porque lo discursivo es una de las maneras de constituir el cuerpo. En términos de Eliseo Verón, se trata de la "materialidad significante de la semiosis social" (1987, p. 141). O también:

La distinción entre acción y discurso no corresponde en modo alguno a la distinción entre 'infraestructura' y 'superestructura'; no corresponde tampoco a la distinción entre 'hacer' y 'decir', puesto que la acción social misma no es determinable fuera de la estructura simbólica e imaginaria que la define como tal ${ }^{26}$ (Sigal y Verón, 1988: 13).

Esto no implica, sin embargo, que lo discursivo sobredetermine a las prácticas. Quizás esta discusión haya sido pensada de ese modo ante la expansión del llamado giro lingüístico en las décadas pasadas. Al respecto, Peter Wade (1999) ha realizado especial énfasis en el abordaje de estos debates reseñando algunos de éstos y organizándolos en lo que denomina el "dualismo material/simbólico", las "distinciones subjetivas/objetivas", o la tensión "unidad/fragmentación". En materia de movimientos sociales esta binarización se traduce en la relación entre sentido y acción, significación y producción, la ya mencionada entre materia y símbolo, o entre cultura y política. Agrega que si bien para autores como Bauman y Bourdieu tal dualismo pretende ser resuelto mediante el entendimiento de la cultura como un "dinámico campo semántico", la oferta postestructuralista de centrarse en la constitución discursiva de las realidades materiales y la materialidad del discurso no resuelve el problema, por lo que algunos abordajes continúan siendo criticados por "refugiarse dentro del discurso perdiendo contacto con la materialidad" (Wade, 1999, p. 449).

Para Wade no es suficiente afirmar que cada práctica tiene "aspectos instrumentales y simbólicos", sino más bien con entender que la necesaria unicidad de toda actividad humana "siguiendo a Marx y otros, "lo que los hombres dicen o imaginan, cómo son narrados, and men in the flesh" son aspectos y dimensiones 
separados y producidos por el observador, ya que no son inherentes al objeto de análisis en sí mismo: "es más útil pensar que cada decir o imaginar es un hacer y cada hacer es un decir” (Wade, 1999, p. 451). Así como los actos de habla (Austin, 1990) a la vez que dicen, producen en tanto actos performativos, podemos pensar el proceso inverso en donde las performances a la vez que actúan, significan. Esto aparece aún más nítido si consideramos la opinión del discípulo de Austin, John Searle (1986), para quien todos los actos de lenguaje son actos de habla aunque sólo algunos de ellos pueden ser considerados en la definición estricta de Austin: los ilocucionarios o actos de habla completos, o perlocucionarios en tanto productores de efectos en sus destinatarios.

De esta forma, realizar un análisis más comprehensivo de las significaciones sociales producidas en la música, en este caso las referidas a nacionalidad en el jazz argentino, implicó un abordaje de al menos las condiciones de producción ${ }^{27}$ de esas significaciones y su materialidad, en un primer término circunscripta a los discursos de y sobre la música.

Así, entendemos que a diferencia de otras músicas populares argentinas como el tango, el denominado folklore, e incluso el rock -aunque por distintas razones, algunas más obvias que otras-, el jazz como práctica musical local no ha sido asociado a los discursos de construcción de las músicas nacionales que cumplieron y cumplen un rol de afirmación de las identidades locales en el marco de los proyectos latinoamericanos de Estado Nación en el siglo XX (Madrid, 2010a). Esto ha sido así a pesar de haber transcurrido casi un siglo de práctica del jazz en la Argentina, y de la participación crucial que han tenido los músicos de jazz -a través de su influencia o de su participación misma- en precisamente esas músicas nacionales.

Esto puede verificarse en el análisis de los discursos en torno a música y nacionalidad del siglo $\mathrm{XX}$ argentino, que colocan al tango y al folklore en el eje urbe/ruralidad, puerto/interior, cosmopolitismo/tradición, disputando allí el sentido de la argentinidad, o en los debates sobre el rock nacional que hacen hincapié en el uso de la lengua castellana por oposición a la sajona. En esta discusión sobre la nacionalidad de la música la relación del jazz con aquellas caracterizadas como nacionales suele históricamente aparecer como conflictiva en el plano discursivo, por ejemplo, a través de la antinomia músicas nacionales versus músicas foráneas, polo este último en donde queda situado el jazz como música negroamericana.

Es por ello que tras despejar un primer análisis superficial que adscribe unívocamente identidades musicales a territorios nacionales -que son los que garantizarían su esencialidad cultural-, argumentamos que una razón clave de la imposibilidad argentina de esta música reside en que, tanto local como internacionalmente, el jazz ha sido racializado como una música negra.

Ahora bien, el discurso que imposibilita la cultura negra en la Argentina no anuló su práctica, aunque ésta nunca haya dejado de resultar problemática por su falta de ubicuidad y/o legitimación en relación a los más diversos subcampos musicales como el erudito, el popular o el comercial. Esta visión es la que nos permite comprender de qué forma se realiza la apropiación por parte de los artistas de prácticas musicales consideradas ajenas, en operaciones que no están exentas de fricciones por su relación con las narrativas culturales hegemónicas, llamativamente dirigidas a cuestiones de racialidad, y que como decíamos no pueden dejar de estar imbricadas con las de nacionalidad.

Es por ello que como segunda etapa del análisis de la músicopoiesis se impone abordar el complejo sonido/performance a partir de una reflexión sobre la corporeidad, que en tanto práctica musical resulta productora de significación vivida (Pelinski, 2005).

La música es un discurso, una práctica, y como tal, una experiencia. Su dimensión simbólica se despliega, por un lado, en forma de un enmascaramiento que 
suele denominarse "identidad cultural". Pero también produce sentidos identitarios no necesariamente narrativos al interior de sus prácticas, intersectadas como músicopoiesis y enraizadas a su vez con los discursos sociales. Así, las identidades creadas sujetas a esas prácticas -narrativas, sonoras, performáticas, que genérica y provisoriamente podríamos denominar discursivas-, son productoras de una significación asequible en la representación y siempre posicionada estratégicamente en relación a un poder. Pero también son experimentadas y encarnadas en la performance, cuyos estudios son además una invitación a pensar en y con la música de qué forma la construcción y significación de las identidades corporeizadas ponen en juego sus fricciones a la hegemonía.

\section{Notas}

1. Se trata de una investigación que abarca nuestras tesis de licenciatura (Corti, 2007), maestría (Corti, 2011) y doctorado -en proceso-, realizadas en la Facultad de Ciencias Sociales de la Universidad de Buenos Aires.

2. Además de los registros que pueden ubicarse en la prensa de entonces, ya en 1999 el grupo Quinteto Urbano editó su primer CD denominado Jazz Contemporáneo Argentino (Acqua Records 2001). El grupo Escalandrum, liderado por Daniel "Pipi" Piazzolla $(\mathrm{h})$, ha referido en varias oportunidades a que su música es "jazz argentino contemporáneo".

3. Hay que destacar también que la construcción de un "jazz argentino" incluye también la asimilación de las prácticas culturales bonaerenses a la totalidad de una idea lo nacional.

4. Sergio Pujol cita entre sus exponentes más relevantes a Adrián laies y Luis Salinas, Luis Nacht, Fernando Tarrés, Ricardo Cavalli, el grupo Escalandrum, el Quinteto Urbano, Ernesto Jodos, El Terceto, y Javier Malosetti, entre otros (Pujol, 2004: 251-272).

5. Sesión improvisatoria colectiva que actualmente se organiza en clubes de jazz.

6. En el ámbito de la ciudad de Buenos Aires la formación pedagógica en música popular se realiza en instituciones de enseñanza superior no universitaria. Desde 1986 existe la Escuela de Música Popular de Avellaneda con carreras de instrumentistas de jazz, y dirigida por músicos del circuito. Desde 1989, la Escuela Popular de Música dependiente del Sindicato del sector, con la Carrera de Músico Intérprete con contenidos de jazz y profesores del área. También muchos músicos argentinos obtuvieron becas en la Berklee College of Music de Boston, famosa por su método de enseñanza jazzística. Más tarde se abrió una subsidiaria de esta institución en Buenos Aires, donde dictan clase los egresados argentinos de esa institución norteamericana. Por otra parte, los intercambios con músicas de otras regiones -principalmente Estados Unidos y Europa- fue facilitada también por la posibilidad de acceder a viajes de estudio en ese momento al alcance de las clases medias. Las nuevas tendencias internacionales podían ser conocidas e incorporadas rápidamente.

7. Por ejemplo, definida en términos temporales como ahora/antes, o nosotros/los viejos (Corti 2007, p. 72).

8. Se denomina standards a los temas que forman parte del repertorio jazzístico reconocido por artistas y público, en donde ingresan como producto de múltiples relecturas realizadas en la producción del discurso musical, y la popularidad adquirida en el reconocimiento de ese discurso. El reconocimiento de una pieza como standard surge también de su incorporación al libro Real Book, un compendio sin autor reconocido de partituras de clásicos de jazz. 
9. Carvalho y Segato proponen en consecuencia establecer, a efectos del análisis, "un corte entre la consciencia propiamente musical del productor (el músico nativo) y la apropiación del producto musical por el discurso no musical del auditor". Esto puede realizarse mediante una experiencia de descentramiento y dislocación del eje a partir del cual vemos y nos posicionamos en las fronteras territoriales para "traer a la luz los movimientos semióticos ocultados por los conceptos de identidad, núcleo, centro, sistema, que están en la base de todas nuestras teorías" (Carvalho y Segato 1994, p. 3).

10. Cuya declaración en guerra contra la burguesía es una gran leyenda del modernismo, como dice Daniel Bell (1976).

11. Utilizamos como fuentes la programación del Jazz Club del Paseo La Plaza (1997-2000), del ciclo Jazz y Vinos del Centro Cultural Konex (2002-2004) y del Netizen Jazz Festival (2004). Cabe destacar que esas denominaciones fueron proporcionadas por los mismos músicos para referir su propia música.

12. A modo de ejemplo, Adrián laies editó el CD Las cosas tienen movimiento (S'Music/EMI 2002) que incluye versiones de composiciones de músicos de rock como Fito Páez y Charly García, o Rodrigo Domínguez quien editó el CD Soy Sauce (BAU Records, 2008), en tributo a Spinetta.

13. Transcribimos algunos ejemplos. Grupo Undersax, mayo 1998: "Versiones a cuatro saxos de standards, latin, y tango contemporáneo". Adrián laies Trio, mayo 1998: "Composiciones y arreglos propios de standards, y versiones jazzísticas de música popular nacional”. Willy González Grupo, marzo 1999: "Temas propios de folklore contemporáneo con lenguaje jazzístico". Dúo Cavalli-Romero, noviembre 2002: "Música de su autoría inspirada en las raíces afro-americanas y composiciones de los más importantes autores de jazz". Grupo Escalandrum, septiembre 2004: "Jazz contemporáneo con sonidos rioplatenses, folk y afrocubanos".

14. Al respecto, en Carambola, Vidas en el jazz latino (2005) Luc Delannoy historiza los orígenes del género en las décadas del veinte y el treinta en Nueva York a partir de la práctica musical de -principalmente- músicos cubanos y portorriqueños emigrados. Con el correr de los años aparecieron músicos de otras nacionalidades, en donde según el autor los argentinos son algunos de los mayor impacto en tanto su "identidad nacional" estaría "cristalizada" en sus expresiones musicales (Delannoy 2005, p. 93), destacándose en ellas el tango "este arranque de melancolía, [que] parece ser la danza y la música argentina del exilio por excelencia, como si el músico hubiera sido siempre un exiliado en su propia tierra..." (Delannoy 2005, p. 106).

15. Según Alejandro Frigerio una de las razones para la suposición de la inexistencia de un candombe argentino actual reside en que "(por lo menos el reciente de la década del setenta) no existe para los estudiosos porque no se corresponde con la forma 'clásica', que se cree desapareció en la segunda mitad del siglo pasado, debido a la disminución numérica y la dispersión geográfica que habría acabado con la comunidad afroargentina como tal", por lo que se utiliza al "candombe uruguayo como modelo, a veces sin siquiera explicitarlo" (Frigerio 2000).

16. La habanera es un género danzario de la zona de influencia del Mar Caribe popularizado en el Río de la Plata a partir de la segunda mitad del siglo XIX.

17. De todas maneras llama la atención que el libro Latitudes africanas del tango de Ortiz Oderigo haya podido ser publicado recién en 2009.

18. Se denomina Guardia Vieja a la generación de músicos de tango activos durante las primeras dos décadas del siglo XX. 
19. Si bien se buscó abarcar diferentes expresiones regionales este proyecto de "unidad nacional" también implicó una idea de homogeneidad que impuso y/o jerarquizó algunas de estas expresiones sobre otras, como la música del noroeste argentino.

20. Al respecto ver Corti, 2011. Fabiola Orquera, por su parte, señala que el músico Atahualpa Yupanqui ponía en cuestión a "quienes utilizan las formas culturales indígenas en beneficio de sus propios intereses", estableciendo "una disputa por la hegemonía de la construcción letrada de lo nativo, oponiendo el "falso gauchismo" a la construcción identitaria que él define y promueve, el indocriollismo" (Orquera 2009, p. 12).

21. El resaltado es nuestro.

22. Género musical bonaerense, asociado al ámbito rural, que se convirtió también en un subgénero urbano dentro del tango.

23. Uno de los géneros musicales emblema del noroeste argentino.

24. Para abundar en el análisis discursivo de estas obras ver Corti, 2007.

25. En tanto sus marcas (o mejor, huellas, ya que puede establecerse la relación entre la propiedad significante y sus condiciones de producción) "permiten reconstruir las operaciones de asignación de sentido que se encuentran subyacentes" (Verón 1987, p. 129).

26. Cursivas en el original.

27. Otro tipo de investigación implicaría también el estudio de las condiciones de recepción, que no está incluido aquí.

\section{Agradecimientos}

Agradezco a la Facultad de Ciencias Sociales de la Universidad de Buenos Aires y al Instituto de Investigación en Etnomusicología de la ciudad de Buenos Aires. Muy especialmente al Dr. Luis Ferreira Makl por su guía, predisposición y generosidad.

\section{Referencias}

Alabarces, Pablo. 2005. "11 Apuntes (once) para una sociología de la música popular en la Argentina". VI Congreso de la Asociación Internacional para el Estudio de la Música Popular, Rama Latinoamericana, Buenos Aires, Argentina, agosto, http://www.hist.puc.cl/iaspm/baires/articulos/pabloalabarces.pdf; consulta: 08/06/2008.

Austin, John. 1990. Cómo hacer cosas con palabras. Paidós, Barcelona.

Bauman, Zygmunt. 2003. "De peregrino a turista, o una breve historia sobre la identidad" en Cuestiones de Identidad Cultural, eds. S. Hall y P. du Gay. Amorrortu, Buenos Aires.

Bell, Daniel. 1976. Las contradicciones culturales del capitalismo. Alianza, Madrid.

Bourdieu, Pierre. 1988. Cosas dichas. Gedisa, Buenos Aires.

Carvalho, José Jorge de y Rita Segato. 1994. "Sistemas abertos e territórios fechados: para uma nova compreensão das interfaces entre música e identidades sociais". Cuadernos de Antropología N 164, Universidad Federal de Brasilia, Brasilia; http://dan.unb.br/multisites/dan/media/docs/Serie164empdf.pdf; consulta 30/11/2009.

Cerulo, Karen. 1997. "Identity Construction: New Issues, New Directions". Annual Review of Sociology, Vol. 23; pp. 385-409, Annual Reviews, Palo Alto CA. 
Chernoff, John Miller. 1979. African Rhythm and African Sensibility. Aesthetics and Social action in African Musical Idioms. The Univeristy of Chicago Press, Chicago and London.

Cirio, Norberto Pablo. 2006. "La presencia del negro en grabaciones de tango y géneros afines" en Buenos Aires Negra. Identidad y Cultura. ed. L. Maronese comp. CPPHC, Buenos Aires.

Cirio, Norberto Pablo. 2010. La historia negra del tango. Todo tiene su "historia negra", pero de ésta estamos orgullosos. Museo Carlos Gardel GCBA, Buenos Aires.

Cook, Nicholas 2007. "Fazendo música juntos ou improvisaçao e seus outros". Per Musi, Revista Académica de Música, Nro. 16; pp 7-20. Universidad Federal de Minas Gerais, Belo Horizonte.

Corti, Berenice. 2007. Identidad del jazz argentino. Cultura y semiótica de un discurso de interpelación. Tesis de Licenciatura, Facultad de Ciencias Sociales Universidad de Buenos Aires, Buenos Aires.

Corti, Berenice. 2010. "Discursos de raza y nación en y sobre Sarmiento: la (im)posibilidad mestiza de la 'blanquedad' porteña". I Jornadas de Estudios Afrolatinoamericanos, Facultad de Filosofía y Letras UBA, Buenos Aires, Argentina, septiembre, http://geala.files.wordpress.com/2011/03/berenice-corti-discursos-de-razay-nacic3b3n-en-y-sobre-sarmiento1.pdf; consulta 19/03/2011.

Corti, Berenice. 2011. Lo afro en el jazz argentino. Identidades y alteridades en la música popular. Tesis de Maestría, Facultad de Ciencias Sociales Universidad de Buenos Aires, Buenos Aires.

Dellanoy, Luc. 2005. Carambola. Vidas en el jazz latino. FCE, México.

Díaz, Claudio. 2009. Variaciones sobre el ser nacional. Una aproximación sociodiscursiva al folklore argentino. Ediciones Recovecos, Córdoba.

Domínguez, María Eugenia 2008. "Música negra en el Río de la Plata: definiciones contemporáneas entre los jóvenes de Buenos Aires". Revista Transcultural de Música 12 ISSN: 1697-0101, Barcelona, Sibe.

http://www.sibetrans.com/trans/trans12/art22.htm: consulta: 11/10/2008.

Ferreira Makl, Luis. 2005. "Conectando estructuras musicales con significados culturales: un estudio sobre sistemas musicales en el Atlántico Negro”. VI Congreso de la Asociación Internacional para el Estudio de la Música Popular, Rama Latinoamericana, Buenos Aires, Argentina, agosto, http://www.hist.puc.cl/iaspm/baires/articulos/luisferreira.pdf; consulta 30/05/2007.

Ferreira Makl, Luis. 2007. "An Afrocentric Approach to Musical Performance in the Black South Atlantic: The Candombe Drumming in Uruguay". Revista Transcultural de Música N \#11 ISSN:1697-0101, Barcelona, Sibe,

http://www.sibetrans.com/trans/trans11/art12.htm; consulta 30/01/2009.

Ferreira Makl, Luis. 2008a. "Música, artes performáticas y el campo de las relaciones raciales. Área de estudios de la presencia africana en América Latina", en G. Lechini, Gladis comp., Los estudios afroamericanos y africanos en America Latina. Herencia, presencia y visiones del otro. CLACSO, Buenos Aires.

Ferreira Makl, Luis. 2008b. "El estudio de la performance musical como proceso de interacción: entre el análisis y el escenario sociocultural. Un estudio de caso de los tambores del candombe afrouruguayo", en M. Fornaro, ed., De cerca, de lejos. Miradas actuales en Musicología de/sobre América Latina. UdelaR (CSEP/EUM), Montevideo. 
Frigerio, Alejandro. 2000. "El Candombe Argentino: Crónica de una muerte anunciada”, en Cultura Negra en el Cono Sur: Representaciones en conflicto, ed. A. Frigerio. EDUCA, Buenos Aires.

Frigerio, Alejandro. 2006. "'Negros' y 'blancos'” en Buenos Aires: repensando nuestras categorías raciales en L. Maronese comp. Buenos Aires Negra. Identidad y Cultura. CPPHC, Buenos Aires.

Frith, Simon. 2003. "Música e Identidad" en Cuestiones de Identidad Cultural, eds. S. Hall y P. du Gay. Amorrortu, Buenos Aires.

García, Valeria. 2003. "Circuito del jazz argentino", Revista Noticias, Edición Extra № 42, noviembre, Buenos Aires.

Goldman, Gustavo. 2008. Herencia africana en el tango 1870-1890. Perro Andaluz, Montevideo.

Hall, Stuart. 1996. "Identidade cultural e diaspora" en Revista de Patrimonio Histórico e artístico nacional Nro. 24. IPHAN, Rio de Janeiro.

Hall, Stuart. 2003. "Introducción: ¿quién necesita 'identidad'”? en S. Hall y P. du Gay eds. Cuestiones de Identidad Cultural, Amorrortu, Buenos Aires.

Hojman, Eduardo. 2001. "Jazz y Argentina”, Diario ABC, Madrid, 15 de septiembre, http://www.jazzhouse.org/files/hojman1.php3; consulta 18/04/2003.

Howard, Judith A. 2000. "Social Psychology of Identities", Annual Review of Sociology, Vol. 26: pp. 367-393. Annual Reviews, Palo Alto CA.

Kwabena Nketia, J. H. 1974. The Music of Africa. W. W. Norton \& Company, New York.

Madrid, Alejandro. 2010a. "Música y nacionalismos", en VVAA, A tres bandas. Mestizaje, sincretismo e hibridación en el espacio sonoro iberoamericano. Ediciones Akal, Madrid.

Madrid, Alejandro. 2010b. Sonares dialécticos y política en el estudio posnacional de la música (inédito). XIX Congreso de la Asociación Argentina de Musicología, Córdoba, Argentina, agosto.

Martin, Alicia. 2006. "Presencias ausentes. El legado africano a la cultura nacional" en Buenos Aires Negra. Identidad y Cultura, L. Maronese comp. CPPHC, Buenos Aires.

Marx, Karl. 1964. "El fetichismo de la mercancía y su secreto" en El Capital Tomo 1. FCE, México.

Nachmanovitch, Stephen. 1991. La improvisación. Planeta, Buenos Aires.

Orquera, Fabiola. 2009. "El 'indocriollismo' en la escena nacional: la narrativa temprana de Atahualpa Yupanqui y su representación cinematográfica", Congreso 2009 de la Asociación de Estudios Latinoamericanos, LASA, Rio de Janeiro, Brasi, junio.

Ortiz Oderigo, Néstor R. 2009. Latitudes africanas del tango, ed. Pablo Cirio. Eduntref, Buenos Aires.

Parret, Herman. 1995. De la semiótica a la estética. Edicial, Buenos Aires. 
Pelinski, Ramón. 2005. "Corporeidad y experiencia musical" Revista Transcultural de Música 9. ISSN: 1697-0101. Barcelona, Sibe, http://www.sibetrans.com/trans/trans9/pelinski.htm; consulta 11/10/2008.

Piedade, Acácio Tadeu de C. 2003. "Brazilian Jazz and Friction of Musicalities". En Jazz Planet, ed. E. Taylor Atkins. University Press of Mississippi, Jackson.

Piedade, Acácio Tadeu de C. 2005. "Música Popular, expressão e sentido: comentários sobre as tópicas na análise da música brasileira". Revista Da Pesquisa, Vol. 1 Nro. 2, Universidad do Estado de Santa Catarina, Florianópolis, http://www.ceart.udesc.br/revista dapesquisa/volume1/numero2/musica/musica popul ar.pdf; consulta 24/08/2009.

Piedade, Acácio Tadeu de C. 2011. "Perseguindo fios da meada: pensamentos sobre hibridismo". Revista Per Musi n. 23, Universidad Federal de Minas Gerais, Belo Horizonte, http://www.musica.ufmg.br/permusi/port/numeros/23/num23 cap 11.pdf;consulta 30/11/2010.

Pradines, César. 2001. "Cómo sobrevive el jazz nacional", en Diario La Nación, Buenos Aires, 16 de Junio, http://www.lanacion.com.ar/315757-como-sobrevive-eljazz-nacional; consulta 20/08/2002.

Pujol, Sergio. 2004. Jazz al Sur. Historia de la música negra en Argentina, Emecé, Buenos Aires.

Rocha Alonso, Amparo. 2004. "La música, las músicas: cuerpo y discurso musical". Material de cátedra para el Seminario Música y Comunicación, mimeo, Carrera de Ciencias de la Comunicación de la Universidad de Buenos Aires, Buenos Aires, http://www.catedras.fsoc.uba.ar/delcoto/textos/Musica\%20musicas.doc; consulta: 20/08/2009.

Schutz, Alfred. 1977. "Making Music Together: a study in social relationship" en Symbolic Anthropology: a reader in the study of symbols and meaning, eds. J. Dolgin, D. Kemnitzer y D. Schneider. Columbia University Press, New York.

Schuller, Günther. 1973. El Jazz, sus raíces y desarrollo. Editorial Víctor Lerú, Buenos Aires.

Searle, John. 1986. Actos de Habla: Ensayo de Filosofía del Lenguaje, Cátedra, Madrid.

Segato, Rita. 2007. La Nación y sus Otros. Raza, etnicidad y diversidad religiosa en tiempos de Política de la Identidad. Prometeo, Buenos Aires.

Sigal, Silvia y Verón, Eliseo. 1988. Perón o Muerte, Hyspamérica, Buenos Aires.

Tagg, Philip. 2000 [1982]. "Analysing popular music: theory, method and practice", en Reading pop: approaches to textual analysis in popular music, coor. Richard Middleton. Oxford University Press, Oxford.

Tagg, Philip. 1987. "Musicology and semiotics of popular music", en Revista Semiotica 66-1/3, Mouton de Gruyter, Amsterdam, pp. 279-298.

Verón, Eliseo. 1987. La semiosis social, Gedisa, Buenos Aires.

Vila, Pablo. 1996. "Identidades narrativas y música. Una primera propuesta para entender sus relaciones", Revista Transcultural de Música 2 ISSN: 1697-0101, Sibe, Barcelona, http://www.sibetrans.com/trans/trans2/vila.htm; consulta 8/072007.

Vila, Pablo. 2000. "Música e identidad. La capacidad interpeladora y narrativa de los 
sonidos, las letras y las actuaciones musicales", en M. Piccini, A. Mantecón y G. Schmilchuk (coords.), Recepción artística y consumo cultural. CONACULTA, INBA y CENIDIAP, México.

Wade, Peter. 1999. "Working Culture. Making Cultural Identities in Cali, Colombia", Current Anthropology Vol. 40, Nro. 4, August-October, The University of Chicago Press, Chicago.

Wortman, Ana. 2009. Entre la politica y la gestión de la cultura y el arte. Nuevos actores en la Argentina contemporánea. Eudeba, Buenos Aires.

\section{Discografía}

Escalandrum. 2006. Misterioso, MDR Records, Argentina.

López Fürst, Baby. 2005. Jazz argentino. Melopea, Argentina.

Pepi Taveira. 2005. Bs. As. Inferno, Buenos Aires, S'Jazz, Argentina.

Quinteto Urbano. 2001. Jazz Contemporáneo Argentino II, Estudio + Vivo, Acqua Records, Argentina. 